\title{
The Metabolic Investigation of Erectile Dysfunction: Cardiometabolic Risk Stratification
}

Martin Miner*

Warren Alpert School of Medicine, Brown University, Providence, RI, USA

*Corresponding author: Martin Miner, Clinical Associate Professor of Family Medicine and Urology, Warren Alpert School of Medicine, Brown University, Men's Health Center The Miriam Hospital, 164 Summit Ave Providence, RI, USA, Tel: +1

508-672-5300; E-mail: Martin_Miner@Brown.edu

Rec date: April 24, 2014, Acc date: May 26, 2014, Pub date: June 02, 2014

Copyright: () 2014 Martin M. This is an open-access article distributed under the terms of the Creative Commons Attribution License, which permits unrestricted use, distribution, and reproduction in any medium, provided the original author and source are credited.

\begin{abstract}
This review discusses the latest evidence for the metabolic investigation of erectile dysfunction as it relates to cardiometabolic risk and visceral adiposity, the key component of metabolic syndrome. The authors illustrate this concept with a clinical example from their own practice, and the metabolic investigation of ED as it relates to the etiology and cardiovascular risk stratification utilizing the latest guidelines of cardiovascular risk released this past year. The authors conclude with the levels of evidence for the use of novel biomarkers in the evaluation of the patient with ED as applied to cardiometabolic risk.
\end{abstract}

Keywords: Metabolic work-up; Erectile dysfunction; Cardiometabolic; Biomarkers; Metabolic syndrome; Visceral adiposity

\section{Introduction}

Erectile dysfunction (ED), defined as the inability to maintain and achieve an erection sufficient for satisfactory intercourse, has a high prevalence and incidence worldwide [1]. A systematic review of epidemiologic evidence undertaken in 2002 showed a clear increase in prevalence in with advancing age, with rates for men younger than 40 years ranging from approximately from $2-9 \%$, compared with $18-86 \%$ for those older than 80 years [2]. Although not life-threatening, it may be a precursor or marker of more serious conditions, particularly coronary artery disease (CAD). Inman et al. [3] have shown when ED occurs in younger men, it is associated with a marked increase in the risk of future cardiac events and that overall ED may be associated with an approximately $80 \%$ higher risk of subsequent CAD.

Sexual function is a complex, multifactorial process. The development of ED is attributable to both psychogenic factors and physiologic alterations in neural, vascular, hormonal and metabolic perturbations, all mediated through endothelial and smooth muscle dysfunction. While this cascade of metabolic parameters can lead to early endothelial dysfunction and eventually, late cardiovascular events, this chapter will focus on the metabolic investigation of erectile dysfunction. Specifically, we will illustrate from our practice a clinical case and the value of the metabolic workup of the ED patient and the evolving concept of "cardiometabolic risk."

Cardiometabolic risk entails the risk of developing any of the following: Type 2 Diabetes (T2 DM), Cardiovascular Disease (CVD), or metabolic syndrome (Met S). The assessment of cardiometabolic risk uses traditional risk factors such as smoking, high LDL-C cholesterol, hypertension, and elevated serum glucose as well as emerging risk factors closely related to abdominal obesity, especially intra-abdominal or visceral obesity. The relationship between traditional cardiovascular risk factors (hypercholesterolemia, hypertension and smoking) and the occurrence of cardiovascular events is well understood. Our increasing understanding of the pathophysiology of cardiovascular disease is now defining value of a range of new cardiovascular risk factors. Risk stratification requires measurement tools of CVD risk that must be valid in the general male population, and measurement tests or biomarkers that help predict cardiac risk [4] ED should become part of this CVD risk assessment.

Traditional models of cardiovascular risk such as Framingham Risk Score (FRS) are weighted toward age, and $80 \%$ of men age $40-59$ will have a low 10- year risk [5]. Incorporating some assessment of lifetime risk has been proposed as an added step to evaluate cardiovascular risk in this young middle-age population noted by Inman with ED to be at particularly elevated CVS risk [3].

New data have emerged to justify a new version, though controversial, to better target lipid management therapies for the reduction of cardiovascular events in the adult population [6]. New guidelines have attempted to address the shortcomings of older risk models. ED guidelines such as Princeton III have attempted to utilize evidence-based evaluation to further stratify men for cardiovascular (CVS) risk following the utilization of keen history taking and traditional risk models to establish the presence of predominantly vasculogenic ED and the volume of subclinical atherosclerotic burden which are markers for subsequent CVS events of MI and CVA in men $[7,8]$. These guidelines are an attempt to elaborate the following questions: [9]

Is a history of ED a harbinger for future cardiovascular risk? Is it best described as a risk marker or risk factor for future CVS events, and just what is the difference?

Are there cost-effective, sensitive, and specific metabolic tests that might indicate increased cardiovascular risk?

Will these tests delineate treatment based on identification of obstructive coronary artery disease (CAD) and atherosclerotic burden and thereby lower future CVS risk and improve erectile function? 


\section{The Metabolic Syndrome: A Cluster of Findings Increasing Risk of Type 2 DM \& CVD- Its Relationship to ED}

Metabolic syndrome (MetS) is a complex disorder with high socioeconomic cost that is considered a worldwide epidemic. MetS is defined by a cluster of interconnected factors that directly increase the risk of Coronary Heart Disease (CHD), other forms of Cardiovascular Atherosclerotic Diseases (CVD), and type 2 DM. Its main components are dyslipidemia (elevated triglycerides and apolipoprotein (apoB)containing lipoproteins, and low High-Density Lipoproteins (HDL), hypertension, and deregulated glucose homeostasis, while abdominal obesity and/or insulin resistance (IR) have gained increasing attention as the core manifestations of the syndrome. Recently, other abnormalities such as chronic proinflammatory and prothrombotic states, non-alcoholic fatty liver disease and sleep apnea have been added to the entity of to the syndrome, making its definition even more complex. Besides the many components and clinical implications of MetS, there is still no universally accepted pathogenic mechanism or clearly defined diagnostic criteria. Furthermore, there is still debate as to whether this entity represents a specific syndrome or is a surrogate of combined risk factors that put the individual at particular risk [10].

The most current definition incorporates the International Diabetes Federation (IDF) and American Heart Association/National Heart, Lung and Blood Institute (AHA/NHLBI) definitions and requires a patient to have any three of the following five conditions [11]:

- Elevated waist circumference (ethnicity specific values, e.g European males $>94 \mathrm{~cm}$ [40in] and females $>80 \mathrm{~cm}$ )

- Triglycerides $1.7 \mathrm{mmol} / \mathrm{l}$ or greater $150 \mathrm{mg} / \mathrm{dL}$

- HDL-chol below $1.03 \mathrm{mmol} / \mathrm{l}[<40 \mathrm{mg} / \mathrm{dL}]$

- $\mathrm{BP}>135 / 85 \mathrm{mmHg}$

- Fasting glucose $>5.6 \mathrm{mmol} / \mathrm{l}[>100 \mathrm{mg} / \mathrm{dL}]$

ED has been linked to multiple selected aspects of the metabolic syndrome, including type 2 diabetes mellitus $[12,13]$, increased fasting blood glucose [14,15] arteriosclerotic disease manifestations [16-18] hypertension $[13,14,19,20]$, and obesity [13-15], and to the metabolic syndrome as defined by different health organizations [14,15,20,21]. Moreover, Bal et al. [15] noted that the risk of ED increased in line with the number of factors of the Met $S$ exhibited by a patient. Several interrelated mechanisms may explain the observed relationship between the Met $\mathrm{S}$ and ED. One obvious mechanism could be a low testosterone level, which has been shown to be associated with moderate and severe ED [22], possibly via a mechanism of diminished NO synthesis [23]. This hypothesis was supported by a report that testosterone treatment increases cavernosal expression of $\mathrm{NO}$ synthetase mRNA in rats [24]. In this way, hypogonadism as a manifestation of the Met $S$ could result in a diminished NO synthesis and subsequent ED. Another mechanism is peripheral arterial insufficiency due to an atherosclerotic disease. The presence of arterial vasculogenic $\mathrm{ED}$ is associated with ischemic heart disease in men $>40$ years old in several studies [25]. Furthermore, men with ED are twice as likely to have sustained a myocardial infarction compared with men without $\mathrm{ED}$, and the risk becomes more pronounced with increasing age [26]. Increasing alpha adrenergic activity has been linked to several established aspects of the Met $S$, and is an attractive potential mechanism that could explain the link between the Met $S$ and ED. Evidence supporting this mechanism has come from a study demonstrating that patients with nonorganic ED have significantly higher sympathetic activity than those without $(\mathrm{p}<0.05)$ [27]. This mechanism has been supported by studies that have concluded that treatment with alpha-receptor antagonists, doxazosin [28], and alfuzosin $[29,30]$ may improve sexual function including ED. This mechanism is also attractive because it explains the link between ED and LUTS, which was confirmed by the Multinational Survey of the Aging Male (MSAM7) study [31,32]. This study included more than 14,000 men, aged 50-80 years, representative of the population of six European countries and the USA [31].

Other mechanisms explaining the link between the Met S and ED involves increased activation of the Rho/Rhokinase pathway, acting downstream of norepinephrine and endothelin1 receptors. Diabetes and hypertension have been linked to increased activity in this pathway [33]. Increased activity in Rho/Rho-kinase pathway results in the inhibition of smooth muscle and subsequent smooth muscle contraction [34]. Although this mechanism has not been specifically demonstrated in erectile tissue, it adds to the body of evidence suggesting that ED is also an expression of the Met $S$ and could arise via this mechanism [35].

Several endocrinopathies are associated with ED. A number of epidemiological data support an inverse relationship between sexual health and testosterone levels, and it is well accepted that testosterone deficiency is a good marker of sexual and physical frailty. However, several other hormones, including $\mathrm{LH}$, prolactin, TSH, and FT4 are involved in sexual functioning and should be investigated in a proper workup of ED [36].

There are several hypotheses concerning the mechanism linking the metabolic syndrome and male hypogonadism. Obesity, especially visceral obesity, is an established aspect of the metabolic syndrome. Activity of aromatase, an adipose enzyme that is involved in the irreversible conversion of testosterone into estradiol,is higher in men who are obese and, consequently, they tend to have a decreased testosterone level and increased estradiol level [37,38]. Thus, the metabolic syndrome provides an endocrine mechanism to explain the development of hypogonadotropic hypogonadism, as it is believed that the effect of estradiol on gonadotropin suppression is more potent than that of testosterone [39]. The findings of Zum off and colleagues, who treated six obese men with oral testolactone (an aromatase inhibitor), support this conclusion. After 6 weeks, men treated with testolactone had higher levels of testosterone and $\mathrm{LH}$ and decreased levels of estrogen compared with their baseline levels [40].

The Hypothalamic-Pituitary-Adrenal (HPA) axis provides yet another mechanism that could explain the link between the metabolic syndrome and hypogonadism. The HPA axis has been shown to be overactive in subjects suffering from the metabolic syndrome, 41 and it is well established that cortisol inhibits the reproductive axis at several levels including secretion of GnRH and $\mathrm{LH}$ and also at the level of the testes themselves [41]. This emerging link between the metabolic syndrome and male hypogonadism via increased aromatase activity, hypogonadotropic hypogonadism and increased activity of the HPA axis seems to suggest that male hypogonadism is also a urological aspect of the metabolic syndrome.

Of interest, a seminal metaanalysis performed by Isadori et al. [42] provides an estimate of the average treatment effects of testosterone therapy in middle-aged men. 29 RCTs were found to be eligible. Overall, 1083 subjects were evaluated, 625 randomized to T, 427 to placebo and 31 to observation (control group). Weighted mean age was 64.5 years (range $49 \cdot 9-77.6$ ) and mean serum testosterone was 
$10 \cdot 9 \mathrm{nmol} / \mathrm{l}$ (range 7.8-19). Testosterone treatment produced: (i) a reduction of $1.6 \mathrm{~kg}$ (CI: $2.5-0.6)$ of total body fat, corresponding to $-6 \cdot 2 \%$ (CI: 9.2-3.3) variation of initial body fat, (ii) an increase in fat free mass of $1.6 \mathrm{~kg}$ (CI: $0 \cdot 6-2 \cdot 6)$, corresponding to $+2 \cdot 7 \%$ (CI: $1 \cdot 1-4 \cdot 4$ ) increase over baseline and (iii) no change in body weight. The effects of $\mathrm{T}$ on muscle strength were heterogeneous, showing a tendency towards improvement only at the leg/knee extension and handgrip of the dominant arm (pooled effect size $=0.3$ standard mean difference (SMD), CI: -0.0 to $0 \cdot 6)$. Testosterone improved bone mineral density (BMD) at the lumbar spine by $+3.7 \%$ (CI: $1 \cdot 0-6 \cdot 4 \%$ ) compared to placebo, but not at the femoral neck, and produced a consistent reduction in bone resorption markers (pooled effect size $=-0.6 \mathrm{SMD}$, CI: $-1 \cdot 0$ to $-0 \cdot 2)$. Testosterone also reduced total cholesterol by $0.23 \mathrm{mmol} / \mathrm{l}$ (CI: -0.37 to $-0 \cdot 10$ ), especially in men with lower baseline $\mathrm{T}$ concentrations, with no change in low density lipoprotein (LDL)cholesterol. A significant reduction of high density lipoprotein (HDL)cholesterol was found only in studies with higher mean T-values at baseline $(-0.085 \mathrm{mmol} / \mathrm{l}, \mathrm{CI}:-0.017$ to -0.003$)$. Sensitivity and metaregression analysis revealed that the dose/type of $\mathrm{T}$ used, in particular the possibility of aromatization, explained the heterogeneity in findings observed on bone density and HDL-cholesterol among studies [42].

Lastly, another meta-analysis recently performed by Corona et al. [43] showed similarly metabolic syndrome changes effected by testosterone. 20 published studies included, 13, 3, and 4 were crosssectional, longitudinal, and RCTs, respectively. Another unpublished RCT was retrieved on www.clinicaltrials.gov MetS patients showed significantly lower $\mathrm{T}$ plasma levels, as compared with healthy individuals. Similar results were obtained when MetS subjects with and without erectile dysfunction were analyzed separately or when NCEP-ATPIII MetS criteria were compared with other definitions. Meta-regression analysis demonstrated that type 2 diabetes (T2DM) increased the MetS-associated T fall. In a multiple regression model, after adjusting for age and BMI, both T2DM and MetS independently predicted low testosterone (adj. $\mathrm{r}=-0.752 ; \mathrm{P}=0.001$ and $-0.271 ; \mathrm{P}=0.05$, respectively). Analysis of longitudinal studies demonstrated that baseline testosterone was significantly lower among patients with incident MetS in comparison with controls $(2.17$ [-2.41;-1.94] nmol/L; $\mathrm{P}=0.0001)$. Combining the results of RCTs, TRT was associated with a significant reduction of fasting plasma glucose, homeostatic model assessment index, triglycerides, and waist circumference. In addition, an increase of high-density lipoprotein cholesterol was also observed [43].

\section{Novel Biomarkers (Metabolic and Imaging) to Clarify CVS Risk in the ED Patient}

By definition, cardiac biomarkers are measurement tests that help predict cardiac risk [44]. They include traditional measurements of cardiovascular risk: the lipid panel; blood sugar; and blood pressure. They can include anthropomorphic measurements such as Waist Circumference (WC), Body Mass Index (BMI) and other measures of visceral obesity. They can include imaging studies such as Coronary Artery Calcification (CAC) as measured by electron-beam computed tomography or computed tomography or Carotid Intima-Media Thickness (CIMT) or carotid plaque. They can be surrogate measures of endothelial function such as peripheral arterial tonometry, or serum asymmetric dimethylarginine (ADMA). They can be surrogate measures of arterial inflammation: highly sensitive C-reactive protein (hsCRP), TNF-alpha, adipokines or Interleukin-6 (IL-6). They can measure insulin resistance and include fasting serum insulin, HOMAIR, fasting glucose, or glycosolated A1C (HgBAlc). Lastly, they might include the measurement of the extremely artherogenic level of small, dense LDL particles, (LDL-P) or Apolipoprotein B (apo-B) as measured by nuclear magnetic resonance.

Therefore, a range of important novel risk factors or biomarkers for cardiovascular disease are associated with the Met $S$, although not yet included within its definition. Most have yet to be validated for efficacy and cost-effective screening in both the asymptomatic or symptomatic ED patient. These include the above noted chronic, lowgrade inflammation, and disturbances in the secretion of bioactive substances from adipocytes ('adipokines') hsCRPapo B and Vitamin D levels [44-47]. The cardiovascular risk factors associated with the metabolic syndrome, whether included within its diagnostic criteria or not, contribute to the progression of atherosclerotic cardiometabolic disease. Current diagnostic and therapeutic approaches do not adequately address these factors and further clarification of the utility of these biomarkers in the ED patient is required.

We examine a few non-traditional markers and evaluate the quality of the evidence for their value as potential markers for cardiometabolic disease and thereby, in the ED patient. These have been graded according to the recommendations of the Centre for Evidence-Based medicine: (http://www.cebm.net/levels_of_evidence.asp) [48]. Levels of evidence have been determined by consensus of the author following review of the present literature.

\section{Waist Circumference (Intra-Abdominal Adiposity) (IAA) in Men with ED: Level of Evidence = 1a}

Intra-Abdominal Adiposity (IAA) drives the progression of multiple risk factors directly, through the secretion of excess free fatty acids and inflammatory adipokines, and decreased secretion of adiponectin. The important contributions of IAA to dyslipidemia and insulin resistance provide an indirect, though clinically important, link to the genesis and progression of atherosclerosis and cardiovascular disease [49-52]. Presence of excess IAA is an important determinant of cardiometabolic risk. IAA is associated with insulin resistance, hyperglycemia, dyslipidemia, hypertension, and prothrombotic/ proinflammatory states. Excess IAA typically is accompanied by elevated levels of C-reactive protein and Free Fatty Acids (FFAs), as well as decreased levels of adiponectin. Abdominal obesity has been shown to be associated with the inflammation cascade, with adipose tissue expressing a number of inflammatory cytokines. Inflammation is now believed to play a role in the development of atherosclerosis and type $2 \mathrm{DM}$. Elevated levels of CRP are considered to be predictive of cardiovascular disease and insulin resistance [51,52].

These components help to explain why excess abdominal adiposity is considered to be a great threat to cardiovascular and metabolic health. Abdominal obesity is associated with multiple cardiometabolic risk factors, including dyslipidemia, elevated blood glucose, and inflammation - all factors leading to the development of CVD and DM in male ED patients $[42,53,54]$. DM is, after age, the greatest risk factor for ED [2]. Patients with DM were three times more likely to develop ED than those who did not have DM $[55,56]$. The prevalence for ED in these patients was as high as 75\% [57-59]. The Cologne Male Survey noted a 4-fold increase in ED in men with DM as compared to the general population [60]. In the Health Professionals Follow-up Study, which involved greater than 30,000 subjects, Bacon et al. [58] found duration of DM strongly associated with incidence of ED. Rhoden et al. [59] found higher glycosolated hemoglobin levels in 
patients with DM to be significantly associated with more severe ED $(\mathrm{p}<0.05)$. The risk of ED in men with $\mathrm{DM}$ is also significantly associated with other diabetic complications such as diabetic neuropathy $(\mathrm{p}<0.05)[60]$.

Adipocytes generate inflammatory cytokines, and patients with obesity and T2DM tend to have a higher inflammatory profile. Inflammatory markers, such as IL-6, TNF-apha, or hsCRP, are elevated and have been associated with impaired endothelial function, cardiovascular events, and ED [61-66].

\section{Testosterone Levels and Cardiometabolic Risk: Level of Evidence $=\mathbf{2 a}$}

Hypogonadism is a common condition in men - especially older men - that can affect both health status and quality of life. Mulligan et al. [67] examined the prevalence rates and odds ratios for selected comorbidities associated with low testosterone levels in 2,162 primary care patients. They observed that the odds ratios of having low levels (hypogonadism is both the presence of low levels and clinical signs and symptoms) were increased in the presence of certain risk factors. The odds ratios for the presence of hypogonadism (the odds of having hyopogonadism if one has this risk factor versus not having the risk factor) being of 2.38 for obesity, 2.09 for diabetes, 1.84 for hypertension and 1.47 for hyperlipidemia [67].

Research to date strongly and consistently shows testosterone replacement therapy (TT), at least over the short term (up to $\sim 3$ years), has positive effects on body composition - decreasing fat mass, and increasing muscle mass - which in turn can reduce the risk for Met $S$ and type $2 \mathrm{DM}$ [68]. Evidence is moderately consistent for TT improving bone mineral density. Research to date also is strong showing TT has positive effects on various aspects of sexual function, though the specific effects differ from study to study. Most studies to date showed that TT increased sexual awareness and arousal, erectile function, and the frequency of spontaneous erections, but was less consistent in enhancing actual sexual behavior and performance [69]. It is beyond the scope of this chapter to address the conflicting issues regarding testosterone and CVS events and mortality. One can simply say that studies thus far both positive and negative are cross-sectional and thereby, inconclusive. Yet, the authors feel it is vital to screen all men with ED for testosterone deficiency, and thereby perhaps gain a sense of a man's overall health and stress. This is especially true in those men with a history of inadequate response to prior PDE5 inhibitors [70].

\section{CAC Potential role in ED Management: Level of Evidence $=1 \mathrm{~b}$}

Coronary Artery Calcium (CAC) scores are better than Carotid Intima Media Thickness (CIMT) as shown in a cohort of 44,052 asymptomatic patients referred for cardiovascular risk stratification. All-cause Mortality Rates (MRs) were calculated after stratifying by age groups and CAC score. Another aim was to determine if Coronary Artery Calcium (CAC) scoring is independently predictive of mortality in young adults and in the elderly population and if a young person with high CAC has a higher mortality risk than an older person with less CAC. Indeed, the value of CAC for predicting mortality extends to both elderly patients and those less than 45 years old. Elderly persons with no CAC have a lower MR than younger persons with high CAC [71].
In another MESA sub analysis, Detrano et al. [72] collected data on risk factors and performed coronary calcium scoring in an ethnically diverse population without cardiovascular disease at entry who were followed for a median of 3.8 years. They found that the adjusted risk of a CVD event was increased by a factor of 7.73 among participants with a CAC score of 101 to 300 compared to those individuals with no coronary calcium [69]. This risk increased to 9.67 among those with CAC scores exceeding 300 [72]. They noted that CAC scores are a strong predictor of incident $\mathrm{CHD}$ and provides predictive value beyond the standard Framingham risk data, regardless of race or ethnicity.

Thus, we propose the use of CAC scoring in men deemed at intermediate risk of CAD with ED according to the Framingham Risk Stratification or patients with low lifetime risk but one that might fall out of the present grading criteria. [8] The absence of CAC is conclusive of minimal to no risk of ASCVD in the following 10-years. The presence of CAC may help guide the clinician regarding appropriate primary prevention therapy and certainly is one of the strongest discriminatory tests for the intermediate risk patient in CVD risk stratification.

\section{The Role for Peripheral Arterial Tonometry (PAT) Assessment, Asymmetric Dimethylarginine (ADMA) as Markers of Endothelial Cell Function in Men with ED: Level of Evidence $=\mathbf{2 a}$}

Because endothelial dysfunction is considered the first step toward the generation of atherosclerotic plaque and can be found in patients with cardiovascular risk factorsthe use of Flow-Mediated Vasodilation (FMD) has long had a role in the evaluation of the pathology of erectile dysfunction [73-75]. Indeed, Kaiser et al. [76] studied 30 men with ED and no other clinical cardiovascular disease and compared them with 27 age-matched controls without ED. The ED group had penile vascular disease present on doppler ultrasound testing (mean peak systolic flow of $28 \mathrm{~cm} / \mathrm{sec}+/-3$ ), an IIEF-5 score of 12.9 vs. 22.3 $(\mathrm{p}=0.000001)$ with a cutoff value for $\mathrm{ED}<21$. While no significant differences were noted in fasting lipids, glucose, homocysteine and CAC scores in the two groups, there was a significant difference in brachial artery flow-mediated vasodilation studies thereby illustrating the idea that ED appears to occur before the development of overt structural or functional systemic vascular disease, and that abnormalities in the penile cavernosal nitric oxide/cyclic GMP vasodilator system may result in ED as an early clinical manifestation of vascular disease [77].

This led to the theory that endothelial dysfunction is believed to be the common initiator of ED and other atherosclerotic diseases. The importance of this study cannot be understated. Men with ED but no other clinical cardiovascular disease were found to have reduced flowmediated vasodilation in the brachial artery in response to sublingual nitroglycerine, indicating endothelial dysfunction and abnormal smooth muscle relaxation. Evidence is accumulating that endothelial dysfunction is an early functional change thought to precede ASCVD changes in the cerebrovascular, coronary, and peripheral circulations [77].

Obesity is associated with increased activation of the renninangiotensin system, which in turn, leads to vasoconstriction and impaired endothelial function [78]. DM is associated with higher levels of Asymmetric Dimethylarginine (ADMA) [79]. ADMA is an endogenous analogue of $\mathrm{L}$-arginine that competively inhibits nitric 
Page 5 of 8

oxide synthase (NOS) [80]. Elevated plasma ADMA levels signify impaired endothelial cell functionand predict cardiovascular events [79,81-85]. A strong link of ADMA to CAD and ED has been reported [86].

Endothelial dysfunction is characterized by a reduction in endogenous nitric oxide activity that may be attributed to an elevation in ADMA levels [87]. Thus, it may be speculated that the elevation of endogenous ADMA may be associated with the systemic manifestations of endothelial dysfunction in patients with cardiovascular risk factors and ED [88].

\section{Vitamin D and Cardiovascular Health: Level of Evidence $=2 \mathbf{b}$}

Vitamin D is known to have a well-defined role in bone and calcium metabolism, but it has also been implicated as a factor in cardiovascular health. Vitamin D deficiency as defined by the American Endocrine Society as less than $20 \mathrm{ng} / \mathrm{ml}$ affects nearly fifty percent of the world's population [89]. It has been observed that the incidence of cardiovascular disease increases with increasing distance from the equator, and correlation with vitamin D deficiency has been proposed as a mechanism [90]. Both the Framingham Offspring Study and the Health Professionals Follow-up Study showed an approximately doubled risk for cardiovascular events in vitamin D deficient subjects [91,92]. Analysis of retrospectively collected data from 27,686 patients in the Intermountain Heart Collaborative Study Group (IHC) demonstrated that vitamin D levels were highly associated with coronary artery disease and myocardial infarction [93]. In the Multi-Ethnic Study of Atherosclerosis, lower $25(\mathrm{OH})$ D concentrations was associated with an increased risk for incident coronary artery calcification, a measure of coronary atherosclerosis [94].

Study of the effects of the Vitamin D Receptor (VDR) has revealed potential mechanisms for the effects of vitamin D on vascular health. Vitamin D receptors are present in all of the key mediators of atherosclerosis including endothelial cells, vascular smooth muscle cells and immune cells [92]. Vascular cell growth, migration and differentiation along with immune response modulation and cytokine expression are tied to activation of the VDR. Vitamin D is also directly involved in the systemic inflammatory response contributing to atherosclerosis [95]. Although interventional studies have not yet shown benefits of vitamin D supplementation in risk reduction, it is clearly evolving as an important marker of risk.

Most importantly, the use of these novel biomarkers and surrogates begs the question whether these markers or risk factors validate an organic cause for ED, and whether modification of these markers/risk factors can improve both ED and lessen overall ASCVD risk? The honest answer is that we do not have clarification of this at present. There remains a disconnect between imaging surrogates and outcomes.

From the above evidence and our experience, we propose the following metabolic investigation of men with $\mathrm{ED}$, including anthropomorphic and vital sign measurements:

2013 ASCVD AHA/ACC Risk Estimator to determine 10-yr and lifetime ASCVD risk (MI and CVA) for men ages 40-59 years [96]

Waist circumference measured at the umbilicus

Blood pressure/heart rate
Fasting insulin and glucose levels

Baseline renal function (BUN/Creatinine)

Fasting lipid profile

Morning total testosterone level

Hs CRP

Vitamin D3 (OH)

If any doubt with use of the 2013 ASCVD Risk Estimator, then CT calcium scoring may clarify risk and treatment options.

When we examine the use of biomarkers, we must distinguish between screening to define a population at risk that we are not currently treating, or reducing surrogate endpoints (e,g. MI, acute coronary syndrome, stroke). These questions, together with the issue posed by Thompson [97] "Could erectile dysfunction serve as a surrogate measure of treatment efficacy in preventive interventions for cardiac disease?" can only be answered by further studies of cardiovascular disease prevention strategies in men with largely vasculogenic ED. Men with ED with or without CVS risk factors, should be considered an 'intermediate' risk group for future cardiovascular events. It is this group of men, particularly under the age of 60 years, who may benefit from utilization of some of these surrogate markers of cardiometabolic risk in a cost-effective manner to stratify them for subsequent aggressive treatment of preventative cardiovascular risk factors. These men, many of whom may be missed by the traditional Framingham risk criteria, may find the risk elaborated with prudent use of these biomarkers or imaging studies. Only further studies of men with vasculogenic ED and preventative measures will provide evidence as to which of the surrogate markers are impactful and efficacious in the delineation of such risk.

\section{Conclusion}

The metabolic investigation of erectile dysfunction involves primarily the investigation of metabolic sequella of visceral adiposity leading to type $2 \mathrm{DM}$ or CVD. This is known as cardiometabolic risk. Older models of cardiovascular risk assessment (FRS) have generally underestimated risk in younger and middle-aged populations. The authors of the new risk models make adjustments for this and introduce the idea of balancing 10-year risk with lifetime risk to aid in decision-making in younger adults. Whether it's lifetime risk or ED that is used to enhance 10-year risk assessment, the concept is the same: to discern those who have started down the path of inflammation, endothelial dysfunction and vulnerable plaque formation, and thereby intervene somewhere upstream from the first ASCVD event. Lifetime risk may be something abstract to most patients, and current evidence does not support its use to guide pharmacotherapy. The value is to motivate therapeutic lifestyle changes. ED is something tangible. It affects mental health and quality of life. Young and middle-aged male patients with ED are likely to make changes that will have an immediate impact on both their CVS risk and overall sexual function.

\section{References}

1. Hatzimouratidis K, Amar E, Eardley I, Giuliano F, Hatzichristou D, et al. (2010) Guidelines on male sexual dysfunction: erectile dysfunction and premature ejaculation. EurUrol 57: 804-814. 
2. Prins J, Blanker MH, Bohnen AM, Thomas S, Bosch JL (2002) Prevalence of erectile dysfunction: a systematic review of population-based studies. Int J Impot Res 14: 422-432.

3. Inman BA, Sauver JL, Jacobson DJ, McGree ME, Nehra A, et al. (2009) A population-based, longitudinal study of erectile dysfunction and future coronary artery disease. Mayo ClinProc 84: 108-113.

4. Marma AK, Berry JD, Ning H, Persell SD, Lloyd-Jones DM (2010) Distribution of 10-year and lifetime predicted risks for cardiovascular disease in US adults: findings from the National Health and Nutrition Examination Survey 2003 to 2006. CircCardiovascQual Outcomes 3: 8-14.

5. Dhaliwal SS, Welborn TA (2009) Central obesity and multivariable cardiovascular risk as assessed by the Framingham prediction scores. Am J Cardiol 103: 1403-1407.

6. Stone NJ, Robinson J, Lichtenstein AH et al. (2013) ACC/AHA guideline on the treatment of blood cholesterol to reduce astherosclerotic cardiovascular risks in adults. J Am CollCardiol

7. Nehra A, Jackson G, Miner M, Billups KL, Burnett AL, et al. (2012) The Princeton III Consensus recommendations for the management of erectile dysfunction and cardiovascular disease. Mayo ClinProc 87: 766-778.

8. Miner M, Nehra A, Jackson G, Bhasin S, Billups K, et al. (2014) All men with vasculogenic erectile dysfunction require a cardiovascular workup. Am J Med 127: 174-182.

9. Castelli WP, Abbott RD, McNamara PM (1983) Summary estimates of cholesterol used to predict coronary heart disease. Circulation 67: 730-734.

10. Kassi E, Pervanidou P, Kaltsas G, Chrousos G (2011) Metabolic syndrome: definitions and controversies. BMC Med 9: 48.

11. Alberti KG, Eckel RH, Grundy SM, Zimmet PZ, Cleeman JI et al. (2009) International Diabetes Task Force on Epidemiology and Prevention, National Heart, Lung and Blood Institute, American Heart Association, World Heart Federation, International Atherosclerosis Society, International Association for the Study of Obesity: harmonizing the metabolic syndrome: a joint interim statement of the International Diabetes Task Force on Epidemiology and Prevention; National Heart Lung, and Blood Institute; American Heart Association; World Heart Federation; International Atherosclerosis Society; and International Association for the Study of Obesity. Circulation 120: 1640-1645.

12. Aslan Y, Sezgin T, Tuncel A, Tekdogan UY, Guler S, et al. (2009) Is type 2 diabetes mellitus a cause of severe erectile dysfunction in patients with metabolic syndrome? Urology 74: 561-564.

13. Saigal CS, Wessells H, Pace J, Schonlau M, Wilt TJ; Urologic Diseases in America Project (2006) Predictors and prevalence of erectile dysfunction in a racially diverse population. Arch Intern Med 166: 207-212.

14. Demir M, Demir C (2011) Assessment of atrial electromechanical coupling characteristics and $\mathrm{P}$-wave dispersion in patients with atrial septal aneurysm. South Med J 104: 385-388.

15. Bal K, Oder M, Sahin AS, KarataÅ ̈ CT, Demir O, et al. (2007) Prevalence of metabolic syndrome and its association with erectile dysfunction among urologic patients: metabolic backgrounds of erectile dysfunction. Urology 69: 356-360.

16. El-Sakka AI, Morsy AM (2004) Screening for ischemic heart disease in patients with erectile dysfunction: role of penile Doppler ultrasonography. Urology 64: 346-350.

17. El-Sakka AI, Morsy AM, Fagih BI, Nassar AH (2004) Coronary artery risk factors in patients with erectile dysfunction. J Urol 172: 251-254.

18. Jackson G (2009) Sexual response in cardiovascular disease. J Sex Res 46: 233-236.

19. Al-Hunayan A, Al-Mutar M, Kehinde EO, Thalib L, Al-Ghorory M (2007) The prevalence and predictors of erectile dysfunction in men with newly diagnosed with type 2 diabetes mellitus. BJU Int 99: 130-134.

20. Tomada N, TomadaI, Botelho F, Cruz F, Vendeira P (2011). Are all metabolic syndrome components responsible for penile hemo dynamics impairment in patients with erectile dysfunction? The role of body fat mass assessment. J. Sex Med 8: 831-839.
21. Kupelian V, Shabsigh R, Araujo AB, O'Donnell AB, McKinlay JB (2006) Erectile dysfunction as a predictor of the metabolic syndrome in aging men: results from the Massachusetts Male Aging Study. J Urol 176: 222-226.

22. Corona G, Mannucci E, Ricca V, Lotti F, Boddi V, et al. (2009) The agerelated decline of testosterone is associated with different specific symptoms and signs in patients with sexual dysfunction. Int J Androl 32: 720-728.

23. Gorbachinsky I, Akpinar H, Assimos DG (2010) Metabolic syndrome and urologic diseases. Rev Urol 12: e157-180.

24. Reilly CM, Zamorano P, Stopper VS, Mills TM (1997) Androgenic regulation of NO availability in rat penile erection. J Androl 18: 110-115.

25. Shamloul R, Ghanem HM, Salem A, Elnashaar A, Elnaggar W, et al. (2004) Correlation between penile duplex findings and stress electrocardiography in men with erectile dysfunction. Int J Impot Res 16: 235-237.

26. Chen CJ, Kuo TB, Tseng YJ, Yang CC (2009) Combined cardiac sympathetic excitation and vagal impairment in patients with nonorganic erectile dysfunction. ClinNeurophysiol 120: 348-352.

27. KirbyRS, O'LearyMP, CarsonC (2005) Efficacy of extended-released oxazosin and doxazosin standard in patients with concomitant benign prostatic hyperplasia and sexual dysfunction .BJU Int 95: 103-109.

28. De Rose AF, Carmignani G, Corbu C, Giglio M, Traverso P, et al. (2002) Observational multicentric trial performed with doxazosin: evaluation of sexual effects on patients with diagnosed benign prostatic hyperplasia. Urolint 68: 95-98.

29. Liguori G, Trombetta C, De Giorgi G, Pomara G, Maio G, et al. (2009) Efficacy and safety of combined oral therapy with tadalafil and alfuzosin: an integrated approach to the management of patients with lower urinary tract symptoms and erectile dysfunction. Preliminary report. J Sex Med 6: 544-552.

30. Kaplan SA, Gonzalez RR, Te AE (2007) Combination of alfuzosin and sildenafil is superior to monotherapy in treating lower urinary tract symptoms and erectile dysfunction. EurUrol 51: 1717-1723.

31. Rosen R, Altwein J, Boyle P, Kirby RS, Lukacs B, et al. (2003) Lower urinary tract symptoms and male sexual dysfunction: the multinational survey of the aging male (MSAM-7). EurUrol 44: 637-649.

32. McVary K (2006) Lower urinary tract symptoms and sexual dysfunction: epidemiology and pathophysiology. BJU Int 97 Suppl 2: 23-28.

33. De Rose AF, Carmignani G, Corbu C, Giglio M, Traverso P, et al. (2002) Observational multicentric trial performed with doxazosin: evaluation of sexual effects on patients with diagnosed benign prostatic hyperplasia. UrolInt 68: 95-98.

34. Faris JE, Smith MR (2010) Metabolic sequelae associated with androgen deprivation therapy for prostate cancer. Curr Opin Endocrinol Diabetes Obes 17: 240-246.

35. Hammarsten J, Peeker R (2011) Urological aspects of the metabolic syndrome. Nat Rev Urol 8: 483-494.

36. Sansone A, Romanelli F, Gianfrilli D, Lenzi A (2014) Endocrine evaluation of erectile dysfunction. Endocrine .

37. Cohen PG (2008) Obesity in men: the hypogonadal-estrogen receptor relationship and its effect on glucose homeostasis. Med Hypotheses 70: 358-360.

38. Vermeulen A, Kaufman JM, Deslypere JP, Thomas G (1993) Attenuated luteinizing hormone $(\mathrm{LH})$ pulse amplitude but normal $\mathrm{LH}$ pulse frequency, and its relation to plasma androgens in hypogonadism of obese men. J Clin Endocrinol Metab 76: 1140-1146.

39. Cohen PG (1998) The role of estradiol in the maintenance of secondary hypogonadism in males in erectile dysfunction. Med Hypotheses 50: 331-333.

40. Zumoff B, Miller LK, Strain GW (2003) Reversal of the hypogonadotropichypogonadism of obese men by administration of the aromatase inhibitor testolactone. Metabolism 52: 1126-1128.

41. Rosmond R, Dallman MF, Björntorp P (1998) Stress-related cortisol secretion in men: relationships with abdominal obesity and endocrine, 
metabolic and hemodynamic abnormalities. J Clin Endocrinol Metab 83: 1853-1859.

42. Isidori AM, Giannetta E, Greco EA, Gianfrilli D, Bonifacio V, et al. (2005) Effects of testosterone on body composition, bone metabolism and serum lipid profile in middle-aged men: a meta-analysis. ClinEndocrinol (Oxf) 63: 280-293.

43. Corona G, Monami M, Rastrelli G, Aversa A, Tishova Y, et al. (2011) Testosterone and metabolic syndrome: a meta-analysis study. J Sex Med 8: 272-283.

44. Chrousos GP (1998) Stressors, stress, and neuroendocrine integration of the adaptive response. The 1997 Hans Selye Memorial Lecture. Ann N Y AcadSci 851: 311-335.

45. Billups KL, Kaiser DR, Kelly AS, Wetterling RA, Tsai MY, et al. (2003) Relation of C-reactive protein and other cardiovascular risk factors to penile vascular disease in men with erectile dysfunction. Int J Impot Res 15: 231-236.

46. Gelfand EV, Cannon CP (2006) Rimonabant: a cannabinoid receptor type 1 blocker for management of multiple cardiometabolic risk factors. J Am CollCardiol 47: 1919-1926.

47. Vasudevan AR, Ballantyne CM (2005) Cardiometabolic risk assessment: an approach to the prevention of cardiovascular disease and diabetes mellitus. Clin Cornerstone 7: 7-16.

48. Centre for Evidence-Based medicine

49. Rathmann W, Haastert B, Herder C, Hauner H, Koenig W, et al. (2007) Differential association of adiponectin with cardiovascular risk markers in men and women? The KORA survey 2000. Int J Obes (Lond) 31 770-776.

50. Yamauchi T, Kamon J, Minokoshi Y, Ito Y, Waki H, et al. (2002) Adiponectin stimulates glucose utilization and fatty-acid oxidation by activating AMP-activated protein kinase. Nat Med 8: 1288-1295.

51. Snijder MB, Heine RJ, Seidell JC, Bouter LM, Stehouwer CD, et al. (2006) Associations of adiponectin levels with incident impaired glucose metabolism and type 2 diabetes in older men and women: the hoorn study. Diabetes Care 29: 2498-2503.

52. Silvestro A, Brevetti G, Schiano V, Scopacasa F, Chiariello M (2005) Adhesion molecules and cardiovascular risk in peripheral arterial disease. Soluble vascular cell adhesion molecule-1 improves risk stratification. Thromb Haemost 93: 559-563.

53. Nikoobakht M1, Nasseh H, Pourkasmaee M (2005) The relationship between lipid profile and erectile dysfunction. Int J Impot Res 17: 523-526.

54. Burke JP, Jacobson DJ, McGree ME, Nehra A, Roberts RO, et al. (2007) Diabetes and sexual dysfunction: results from the Olmsted County study of urinary symptoms and health status among men. J Urol 177: 1438-1442.

55. Ponholzer A, Temml C, Mock K, Marszalek M, Obermayr R, et al. (2005) Prevalence and risk factors for erectile dysfunction in 2869 men using a validated questionnaire. EurUrol 47: 80-85.

56. Saigal CS, Wessells H, Pace J, Schonlau M, Wilt TJ; Urologic Diseases in America Project (2006) Predictors and prevalence of erectile dysfunction in a racially diverse population. Arch Intern Med 166: 207-212.

57. Fonseca V, Jawa A (2005) Endothelial and erectile dysfunction, diabetes mellitus, and the metabolic syndrome: common pathways and treatments? Am J Cardiol 96: 13M-18M

58. Vinik A, Richardson D (1998). Erectile dysfunction in diabetes. Diabetes Rev 6:16-33.

59. Fedele D, Coscelli C, Santeusanio F, Bortolotti A, Chatenoud L, et al. (1998) Erectile dysfunction in diabetic subjects in Italy. GruppoItaliano Studio Deficit ErettileneiDiabetici. Diabetes Care 21: 1973-1977.

60. Braun M, Wassmer G, Klotz T, Reifenrath B, Mathers M, et al. (2000) Epidemiology of erectile dysfunction: results of the 'Cologne Male Survey'. Int J Impot Res 12: 305-311.

61. Bacon CG, Hu FB, Giovannucci E, Glasser DB, Mittleman MA, et al. (2002) Association of type and duration of diabetes with erectile dysfunction in a large cohort of men. Diabetes Care 25: 1458-1463.
62. Rhoden EL, Ribeiro EP, Riedner CE, Teloken C, Souto CA (2005) Glycosylated haemoglobin levels and the severity of erectile function in diabetic men. BJU Int 95: 615-617.

63. Gazzaruso C, Pujia A, Solerte SB, Amici ED, Emanuele E, et al. (2006) Erectile dysfunction and angiographic extent of coronary artery disease in type II diabetic patients. Int J Impot Res 18: 311-315.

64. Naya M, Tsukamoto T, Morita K, Katoh C, Furumoto T, et al. (2007) Plasma interleukin-6 and tumor necrosis factor-alpha can predict coronary endothelial dysfunction in hypertensive patients. Hypertens Res 30: $541-548$

65. Vlachopoulos C, Aznaouridis K, Ioakeimidis N, Rokkas K, Vasiliadou C, et al. (2006) Unfavourable endothelial and inflammatory state in erectile dysfunction patients with or without coronary artery disease. Eur Heart J 27: $2640-2648$

66. Giugliano F, Esposito K, Di Palo C, Ciotola M, Giugliano G, et al. (2004) Erectile dysfunction associates with endothelial dysfunction and raised proinflammatory cytokine levels in obese men. J Endocrinol Invest 27: 665-669.

67. Mulligan T, Frick MF, Zuraw QC, Stemhagen A, McWhirter C (2006) Prevalence of hypogonadism in males aged at least 45 years: the HIM study. Int J ClinPract 60: 762-769.

68. Buvat J, Maggi M, Guay A, Torres LO (2013) Testosterone deficiency in men: systematic review and standard operating procedures for diagnosis and treatment. J Sex Med 10: 245-284.

69. Miner M, Canty DJ, Shabsigh R (2008) Testosterone replacement therapy in hypogonadal men: assessing benefits, risks, and best practices. Postgrad Med 120: 130-153.

70. Shabsigh R, Kaufman JM, Steidle C, Padma-Nathan H (2004). Randomized study of testosterone gel as adjunctive therapy to sildenafil in hypogonadal men with erectile dysfunction who do not respond to sildenafil alone. J Urol 172: 658-663.

71. Tota-Maharaj R, Blaha MJ, McEvoy JW, Blumenthal RS, Muse ED, et al. (2012) Coronary artery calcium for the prediction of mortality in young adults $<45$ years old and elderly adults $>75$ years old. Eur Heart J 33: 2955-2962.

72. Detrano R, Guerci AD, Carr JJ, Bild DE, Burke G, et al. (2008) Coronary calcium as a predictor of coronary events in four racial or ethnic groups. N Engl J Med 358: 1336-1345.

73. Cooke JP (2000) The endothelium: a new target for therapy. Vasc Med 5: 49-53.

74. Lekakis J, Papamichael C, Vemmos C, Stamatelopoulos K, Voutsas A, et al. (1998) Effects of acute cigarette smoking on endothelium-dependent arterial dilatation in normal subjects. Am J Cardiol 81: 1225-1228.

75. Higashi Y, Sasaki S, Nakagawa K, Matsuura H, Chayama K, et al. (2001) Effect of obesity on endothelium-dependent, nitric oxide-mediated vasodilation in normotensive individuals and patients with essential hypertension. Am J Hypertens 14: 1038-1045.

76. Daniel R. Kaiser, Kevin Billups, Carol Mason, Rebecca Wetterling, Jennifer L. Lundberg et al. (2004). Impaired brachial artery endotheliumdependent and -independent vasodilation in men with erectile dysfunction and no other clinical cardiovascular disease. J Am CollCardiol 43:179-184.

77. Shabsigh $\mathrm{R}$ (2005) Correlation between erectile dysfunction and metabolic syndrome. In: Sadovsky R. ed. Heart of the Matter: Erectile Dysfunction as an Early Sign of Vasculopathy. Livingston, NJ: CogniMed Inc.14-21.

78. Segura J, Ruilope LM (2007) Obesity, essential hypertension and reninangiotensin system. Public Health Nutr 10: 1151-1155.

79. Yamagishi S, Ueda S, Nakamura K, Matsui T, Okuda S (2008) Role of asymmetric dimethylarginine (ADMA) in diabetic vascular complications. Curr Pharm Des 14: 2613-2618.

80. Palmer RM, Ferrige AG, Moncada S (1987) Nitric oxide release accounts for the biological activity of endothelium-derived relaxing factor. Nature 327: 524-526. 
Citation: Miner M (2014) The Metabolic Investigation of Erectile Dysfunction: Cardiometabolic Risk Stratification. J Diabetes Metab 5: 386. doi: $10.4172 / 2155-6156.1000386$

Page 8 of 8

81. Juonala M, Viikari JS, Alfthan G, Marniemi J, Kähönen M, et al. (2007) Brachial artery flow-mediated dilation and asymmetrical dimethylarginine in the cardiovascular risk in young Finns study. Circulation 116: 1367-1373.

82. Ardigo D, Stüehlinger M, Franzini L, Valtueña S, Piatti PM, et al. (2007) ADMA is independently related to flow-mediated vasodilation in subjects at low cardiovascular risk. Eur J Clin Invest 37: 263-269.

83. Valkonen VP, Päivä H, Salonen JT, Lakka TA, Lehtimäki T, et al. (2001) Risk of acute coronary events and serum concentration of asymmetrical dimethylarginine. Lancet 358: 2127-2128.

84. Friedrich Mittermayer, KatarzynaKrzyzanowska, Markus Exner, Wolfgang Mlekusch, Jasmin A et al (2006). Asymmetric dimethylarginine predicts major adverse cardiovascular events in patients with advanced peripheral artery disease. ArteriosclerThrombVascBiol26:2536-2540.

85. Schnabel R, Blankenberg S, Lubos E, Lackner KJ, Rupprecht HJ, et al. (2005) Asymmetric dimethylarginine and the risk of cardiovascular events and death in patients with coronary artery disease: results from the AtheroGene Study. Circ Res 97: e53-59.

86. Maas R, Wenske S, Zabel M, Ventura R, Schwedhelm E, et al. (2005) Elevation of asymmetrical dimethylarginine (ADMA) and coronary artery disease in men with erectile dysfunction. EurUrol 48: 1004-1011.

87. Cooke JP (2000) Does ADMA cause endothelial dysfunction? ArteriosclerThrombVascBiol 20: 2032-2037.

88. Kielstein JT, Impraim B, Simmel S, Bode-Böger SM, Tsikas D, et al. (1989) Cardiovascular effects of systemic nitric oxide synthase inhibition with ADMA in humans. Circulation 2004; 109:172-177. Judd S, Tangpricha V. Vitamin D Deficiency and Risk for Cardiovascular disease. Lancet 1:613.
89. Holick MF, Binkley NC, Bischoff-Ferrari HA, Gordon CM, Hanley DA, et al. (2011) Evaluation, treatment, and prevention of vitamin D deficiency: an Endocrine Society clinical practice guideline. J ClinEndocrinolMetab 96: 1911-1930.

90. Judd S, Tangpricha V (1989) Vitamin D Deficiency and Risk for Cardiovascular disease. Lancet. 1:613.

91. Wallis DE, Penckofer S, Sizemore GW (2008) The "sunshine deficit" and cardiovascular disease. Circulation 118: 1476-1485.

92. Kühn T, Kaaks R, Teucher B, Hirche F, Dierkes J, et al. (2013) Plasma 25hydroxyvitamin $\mathrm{D}$ and its genetic determinants in relation to incident myocardial infarction and stroke in the European prospective investigation into cancer and nutrition (EPIC)-Germany study. PLoS One 8: e69080.

93. Mullie P, Autier P (2010). Relation of Vitamin D Deficiency to Cardiovascular Disease. Am J Cardiol. 106:963-968.

94. de Boer IH, Kestenbaum B, Shoben AB, Michos ED, Sarnak MJ, et al. (2009) 25-hydroxyvitamin D levels inversely associate with risk for developing coronary artery calcification. J Am SocNephrol 20: 1805-1812.

95. Danik JS, Manson JE (2012) Vitamin d and cardiovascular disease. Curr Treat Options Cardiovasc Med 14: 414-424.

96. Goff Jr DC, Lloyd Jones DM, Bennett G, O'Donnell CJ, Coady S, et al. (2013) ACC/AHA Guideline on the Assessment of Cardiovascular Risk. Circulation.

97. Thompson IM, Tangen CM, Goodman PJ, Probstfield JL, Moinpour CM, et al. (2005) Erectile dysfunction and subsequent cardiovascular disease. JAMA 294: 2996-3002. 